\title{
What's the Big Idea with CS Education in K-12?
}

\author{
Tim Bell \\ Department of Computer Science and Software Engineering \\ University of Canterbury \\ New Zealand \\ Tim.Bell@canterbury.ac.nz
}

\begin{abstract}
Computer Science is seen in many different ways in society; some may consider it to be an esoteric collection of jargon-laden skills, while others view it as an essential topic of study for all citizens. Many of us are very passionate about sharing our enthusiasm for the subject with others, and we are at a time in history where much of the hard work to get the public to understand that it is something special is starting to bear fruit, as we see Computer Science and Computational thinking appearing in K-12 curricula around the world. But what is it about Computer Science that makes it so important and exciting? Is it a subject in its own right that deserves space in the curriculum? We will explore the reasons that young students should become engaged with the subject, illustrated using an Unplugged perspective.
\end{abstract}

\section{CCS Concepts}

- Social and professional topics K-12 education - Social and professional topics Computing education $•$ Social and professional topics Computational thinking • Applied computing • Applied computing Education

\section{Keywords}

Computer Science Unplugged; K-12; Computing Education

\section{ACM Reference format:}

Tim Bell. 2018. What's the Big Idea with CS Education in K-12??. In SIGCSE '18: 49th ACM Technical Symposium on Computer Science Education, Feb. 21-24, 2018, Baltimore, MD, USA. ACM, NY, NY, USA, 6 pages. https://doi.org/10.1145/3159450.316087

\section{BIOGRAPHY}

Tim Bell is a professor in the Department of Computer Science and Software Engineering at the University of Canterbury. His

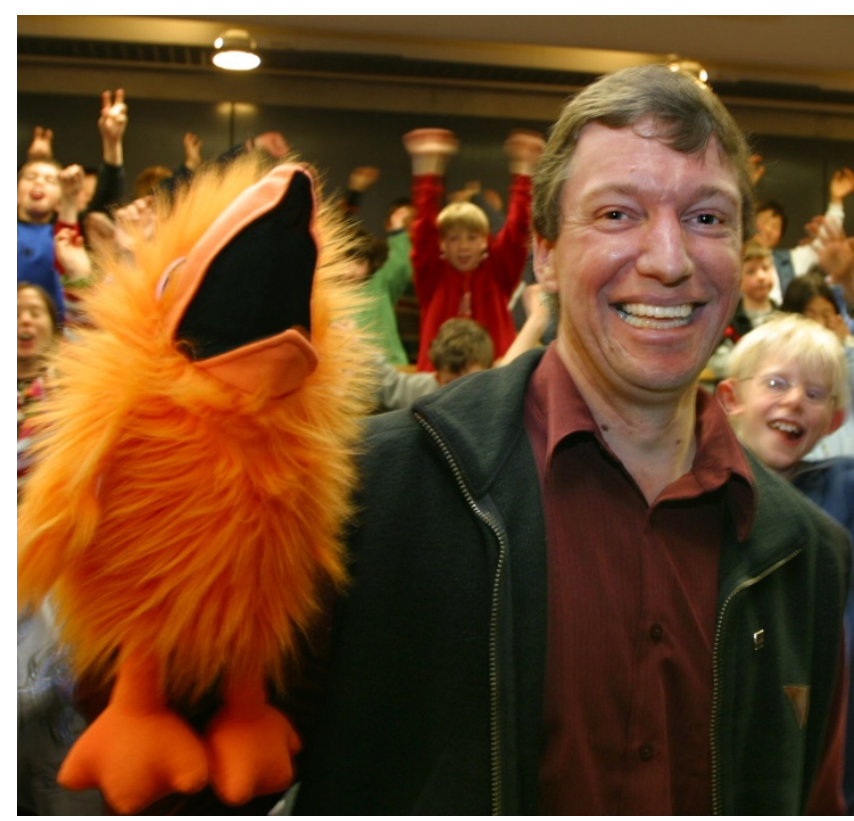

"Computer Science Unplugged" project is being widely used internationally with the supporting materials (books and videos) having been translated into over 20 languages. Tim's awards for his work in computing education including the ETH (Zurich) ABZ International Honorary Medal for Fundamental Contributions in Computer Science Education (in 2013) and the IITP President's Award for Contribution to the IT Profession in 2014. Since 2008 he has been actively involved in the design and deployment of teaching Computer Science and Computational Thinking in New Zealand schools.
Permission to make digital or hard copies of part or all of this work for personal or classroom use is granted without fee provided that copies are not made or distributed for profit or commercial advantage and that copies bear this notice and the full citation on the first page. Copyrights for third-party components of this work must be honored. For all other uses, contact the Owner/Author.

SIGCSE '18, February 21-24, 2018, Baltimore, MD, USA

(c) 2018 Copyright is held by the owner/author(s).

ACM ISBN 978-1-4503-5103-4/18/02.

https://doi.org/10.1145/3159450.3166087 